\title{
ENHANCEMENT OF TOTAL TECHNICAL LIFE OF AERO PLANES
}

\author{
${ }^{1}$ Balachandran, A., ${ }^{2}$ P.R. Suresh, ${ }^{3}$ Shriram K. Vasudevan and ${ }^{3}$ Kaushik Velusamy \\ ${ }^{1}$ Centre for Research and Development, PRIST University, Tanjore, India \\ ${ }^{2}$ Department of Mechanical Engineering, NSS College of Engineering, Palakad, India \\ ${ }^{3}$ Department of Computer Science, Amrita University, Coimbatore, India
}

Received 2013-10-30, Revised 2013-11-09; Accepted 2013-11-22

\begin{abstract}
Government of India spends most of its income towards strengthening the Army, Air Force and Navy. Out of the amount spent for this, about $80 \%$ of money is spent on technology advancement and maintenance. We are coming in particular now about the Air Force and its fighter jets along with other flying machines as well. Taking Mirage-2000 as an instance, the complete project has been planned to be carried out. The total technical life i.e., effective flying time for a fighter plane is generally around $5000 \mathrm{~h}$ of flying/25 years approximately. In between, there can be services done at periodic intervals. Means, it will be permitted to fly up to $2000 \mathrm{~h}$, then servicing can be done with which further flying can be permitted. The point here is, even if a flight has not flown for $2000 \mathrm{~h}$, but reached 12 years of time frame, it has to be serviced, which is definitely under utilization of the machine. Also a particular flight can be flown for $2000 \mathrm{~h}$. well before time, say 8 years; even then the servicing has to be carried out. A flight might have been subjected to tough flying (GConditions) conditions in a short span of time. In such case, it undergoes tough wear and tear through which more fatigue is also possible. In this case this machine has to be given more attention as it has been used under extreme conditions. On the other side of the coin, for the same flying hours, another flight which had flown under straight/study conditions will also get the same treatment. It is not fair to treat a guy who is working hard and a guy who has not done that! Few researchers have worked on understanding and even proposing fault diagnositcs. But, there is a lot more to do in cost savings point of view. This study aims at bringing a solution, which has an embedded system in place which would fetch all the critical information during flight and with which optimum usage can be obtained and thereby increasing the effective flying time of the flight through which we get better results economically, technically and avoiding over maintenance. This will eventually find out a way to exploit the aircraft more effectively with cutting down the unnecessary cost.
\end{abstract}

Keywords: Embedded System, Aircraft, Maintenance Utilization, Flying Hours, Prognostics

\section{INTRODUCTION}

The useful life (Total Technical Life) of aircraft are calculated based on various factors like, design parameters, various tests conducted during experimental stage to sustain stress and fatigue during operation, environmental conditions at which it operates, various periodical and non-periodical maintenance activities to be performed during the operation and finally factor of safety margin. The useful life is fixed thereafter on
Hourly basis or calendar basis. However, the utilization of each and every aero plane differs during their useful period and standard fixing of life either in hourly basis or by calendar basis will limit their utilization. This research work is to find out some means by which we analyze the utility of aero plane from engineering angle and limit the life either by Fatigue index or stress index basis or by some means which will be based on actual utilization. This will allow the operators to use the aero planes to their full design potential rather than underutilization.

Corresponding Author: Balachandran A., Centre for Research and Development, PRIST University, Tanjore, India 
The life so fixed is for the entire fleet of aero planes and all these planes are withdrawn from operation after reaching the prescribed life limit. However during the period of operation, all these planes do not undergo same amount of stress/fatigue and there is a possibility of certain residual life left over. For example, consider two aero planes (aero plane A and aero plane B) of same fleet whose useful life is fixed as say $5000 \mathrm{~h} / 25$ years whichever is earlier. These values have been arrived at after various experimental design analyses. In actual usage, let us assume aero plane A is always flying at straight and steady level condition without undergoing maximum stress/fatigue level. On the other hand, aero plane B may be undergoing always aerobatics, various maneuvers and tight sharp turns thereby experiencing a great amount of stress. At the end of their life both aero planes $A$ and $B$ will be discarded as they have completed their prescribed life by manufacturers. However we can see aero plane $\mathrm{A}$ is underutilized due to the fact that it has not operated to its maximum levels of design parameters. Still it had to be withdrawn from service, due to only fact that it has reached the operating limits prescribed by manufacturers/designers.

By carrying out life cycle analysis of each plane in a scientific manner (for example fatigue analysis at different stages of period of operation), there is a possibility to increase the life of aero plane thereby not only we can use the aero planes to its full potential but also save a huge amount of money. The per hour flying cost of passenger/commercial/fighter aero plane may cost anywhere between 5 lakhs to 10 lakhs depending on type of aero plane. If we can enhance the useful life, it will lead to huge savings. This research will focus on both design and maintenance aspects to help the designer and manufacturer to increase the useful life of plane by observing actual stress/fatigue level and enhance the life to actual conditions rather than the theoretical conditions.

Li et al. (2012) has done an extensive research on the fatigue which was useful to understand the fatigue related factors.

\subsection{Problem Statement}

To find out actual data of stress of an aeroplane by means of capturing various parameters in on-board monitoring system thereby enhancing the useful life. Not much has been done in this area in the research front. Many have done a lot of work on prognostics as
(Kechida and Debbache, 2005) done. But, enhancing TTL has remained an untouched area. In order to determine the means to find out actual utilization, various tools are required. Some of them are given below:

- While design stage of planes, additional components like sensors, fatigue meters, gravity reading have to be introduced

- Many open loop systems of aircraft will have to be curved into closed loop system thereby providing valuable feedback

- More effective mechanism of monitoring important parameters requires to be introduced

- Periodic maintenance activities planned will have to be done in a systematic manner with additional inputs for future analysis

- Environmental conditions in which it operates need to be analyzed (Heat, moisture, temperature conditions). These aspects need to be captured as part of flying parameters

- On board condition and monitoring systems need to be strengthened

- Standby systems in case of failure of main systems on basic flying equipment should be ensured

- In between the life, at various withdrawals certain activities should be performed to see that how the designed values are same as actual values

\subsection{Literature Review}

The "lifespan" of an airliner is not truly measured in time, but pressurization cycles. Each time the aircraft is pressurized during flight it's fuselage is subjected to stress. The "lifespan" of the aircraft is also dependent on the metal fatigue and cracks. Each time when an aircraft is pressurized/utilized during flight, its fuselage and wings are hassled. An aircraft can be kept flying more or less indefinitely. However, there will eventually reach a point where the maintenance starts costing so much it just doesn't make sense to keep going. Once you start having to replacing things, it gets rather costly. When the maintenance costs keeps increasing than normal, it's usually time to drop. Generally, Design Economic Life is 25 years. It does not mean it cannot be maintained; only that it would be more expensive to maintain. The "service life of 25 years" is as generalization that figures 51,000 flight hours and 75,000 pressurization cycles for most of the civil aircraft. If an aircraft is used on long haul routes, 
it experiences relatively few pressurization cycles in it's "life", it will last far beyond 25 years. Example scenario in-northwest Airlines. Aircraft which are repeatedly used and flown on petite hops will reach their useful life greatly earlier. Example scenario in aloha airlines case. Aircraft used on extensive flights experience rarer pressurization cycles and can last more than two decades. There are $747 \mathrm{~s}$ out there that are 25 or 30 years old. The fuselage is most susceptible to fatigue, but the wings are even not an exception too, especially on short hauls where an aircraft goes through pressurization cycles every day.

Feng et al. (2007), discussed clearly on how to obtain the minimum lifecycle cost for the aircraft and lot of information has been understood through the paper.

The lifetime of an aircraft can be expressed in terms of flight-hours and in terms of flights an aircraft makes, which is most convenient, depends on the part. For parts like the landing gear and the fuselage (due to fatigue caused by repeated pressurization) it is most convenient to express their lifetime in amount of flights. For parts like the engine, it is most convenient to express the lifetime in the flight-hours. Every time an Aircraft comes out of a C/D check, its structurally Airworthy until the next Major Check. Depending on the Airline/Aircraft scheduled checks are carried out at Various Intervals.

Above values is an Example and can vary. There is also a calendar period attached, in case of underutilization of Aircraft.

\subsection{Existing Testing Methodologies in Aircraft}

The experiment in emerging an easier and less costly inspection strategy is to project a technique that can be used from the skin side (of the wing), that does not require removal of the fastener and that provides the same or better resolution than the conventional method of removing the fastener. Not having to remove the fastener is a great option to save money.

One commonly used method of NDE is ultrasonic phased-array testing, which analyzes the echoes from ultrasonic waves to reveal imperfections inside a material. By using several ultrasonic beams instead of just one, then varying the time delays between the beams, inspectors can look inside a material at different locations and depths, thereby determining the size and shape of any defects. At present, milliondollar robotic inspection systems equipped with phased arrays are being used to inspect wings and composite fuselages for large commercial aircraft and jetfighters before they fly.
Corrosion is an unwanted attack on the material, resulting from chemical or electro-chemical reactions with the surrounding environment. Corrosion resistance is an important factor to consider during material selection. There are many forms of corrosion. Besides general corrosion there are galvanic or contact corrosion, which occurs due to a difference in electric potential between touching parts, inter crystalline corrosion, where the more active edges of the crystals are attacked while the rest of the crystals remain intact, stress corrosion, where mechanical stress increases the chemical activity of the material and fretting corrosion, where wear between surfaces results in corrosion products (hard oxides) increasing the local corrosive effect.

Parking an aircraft outside instead of in a hangar increases the aging process. Characteristically, the true existence of an aircraft shouldn't be measured in time or years, nevertheless in cycles. One full takeoff/landing is one cycle. As most people will say, an airplane can last indefinitely if properly maintained.

\subsection{Current Usage Scenario}

- $100 \%$ component is installed in the correct places

- The aircraft has got residual life. All the components fitted on the aircraft are serviceable

- Pre-flight inspection has been carried out. i.e., The necessary immediate checks like tyre pressure, fuel, all the basic checks of engine and the aircraft are fully fit for flying

- Foreign object damage checks are completed

- All the necessary documentation had been done and kept ready

- $\quad$ Supervisor check (certain percentage of total checks) is done by the ground engineer and he has certified to that effect

- After one landing and take-off is completed, a check called turn around check or servicing need to be done before the aircraft is clear for second flying

Turn around check includes the following:

- $\quad$ Based on pilot input-snag assessment and repair (replacement of component) as required

- Airframe checks, engine checks various oil level checks+go and no go checks+retrieval of information about the previous flight and heavy landing checks if necessary and fuel checks have been carried out 
- Last flying check-After the last flight of the day, the aircraft need to check the following. The aircraft surface visual check and check foreign object damage checks

Before energising the aircraft, we have to ensure the following.

The aircraft is parked in a free and plain surface. It is free from encumbrances. The aircraft is facing the safe direction. All the safety pins are in right places. Safety rules and regulations are incorporated.

Before start-up of the aircraft, ensure the following.

All the safety pins are removed. All the safety and blanking covers are removed. All the ground support equipment are placed. All the switches in the cockpit are placed at correct position. During starting follow correct start-up procedure, once aircraft started remove all the aircraft ground support equipment and allow pilot to carry out the ground checks before taxing (start). Follow the ground taxing procedure for aircraft to reach the runway and based on the ATC clearance pilot follow take-off procedure. Once done, altitude has to be reached which is already determined and once again the system functionality checks have to be carried out. Westervelt et al. (2005) has done an extensive research on understaning the maintanence of ground station and the same has been read to understand the process. The system checks include, undercarriage closed and locked check, basic electrical checks, flight information checks, head up display, head down display information check, passenger comfort checks (Air Conditioning and pressurisation check). Apart from these, Engine vital information check is mandatory, particularly in single engine flight. Figure 1-4 can be used for the understanding.

\subsection{Factors Under Consideration for Testing}

As shown in the Fig. 4 the following are the factors taken for consideration which has a major impact of the total technical life of the aircraft:

- Landing loads (Compression load Factor)

- Engine aircraft interface (Interface load factor)

- Fuse lage-Main body (Creap load factor)

- Wing root joint (Stress factor)

- Upper wing (compression load factor)

- Fuse lage (longitudinal tension/bending load factor)
One can refer to the various testing process and related time period meant for it from Table 1.

\subsection{Proposed Solution}

Inputs to be received from the aircraft:

1. Fatigue index (Accelerometers, G-Meters (gravity)

2. Stress measurement (Forces acting on the machine):

- Undercarriage

- Engine aircraft interface

- Fuselage (Creep load)

- Wing Roots

- Wing

- Central fuselage-main body

3. Components of Engine (Rotary and Static):

- Treat the Engine as an Entity by itself-100 h (on the whole)

- Treat it as combo of Modules

- Air Intake

- On condition/Bird hit

- Compressor

- $300 \mathrm{~h}$

- Combustion chamber (creep)

- $300 \mathrm{~h}$

- Nozzle guide vanes (Guides the flow to the correct angle of turbine)

- $300 \mathrm{~h}$

- Turbine. (Heat to Mechanical conversion)

- $165 \mathrm{~h}$

- Exhaust nozzle (Newton's third law)

- On condition/Bird hit

Apart from the 26 existing high end processing computers we make use of the 27th single board processing computer Raspberry pi to analyse the big data from the above mentioned factors and determine the results.

The Raspberry Pi is a credit-card sized computer. ARM1176JZF-S $700 \mathrm{MHz}$ processor with overclocking, up to $1 \mathrm{GHz}$, videoCore IV GPU, 256 megabytes of RAM, later upgraded to $512 \mathrm{MB}$. Arch Linux ARM distributions with 2 usb port, ethernet port, audio/video jack, high defintion media interface, SD card, 5v power supply.

Figure 5-7 reveals the appearances of the embedded kits as Rasberry Pi, Beagle board and ATMEL kit. 
Balachandran A. et al. / Journal of Computer Science 10 (3): 403-410, 2014

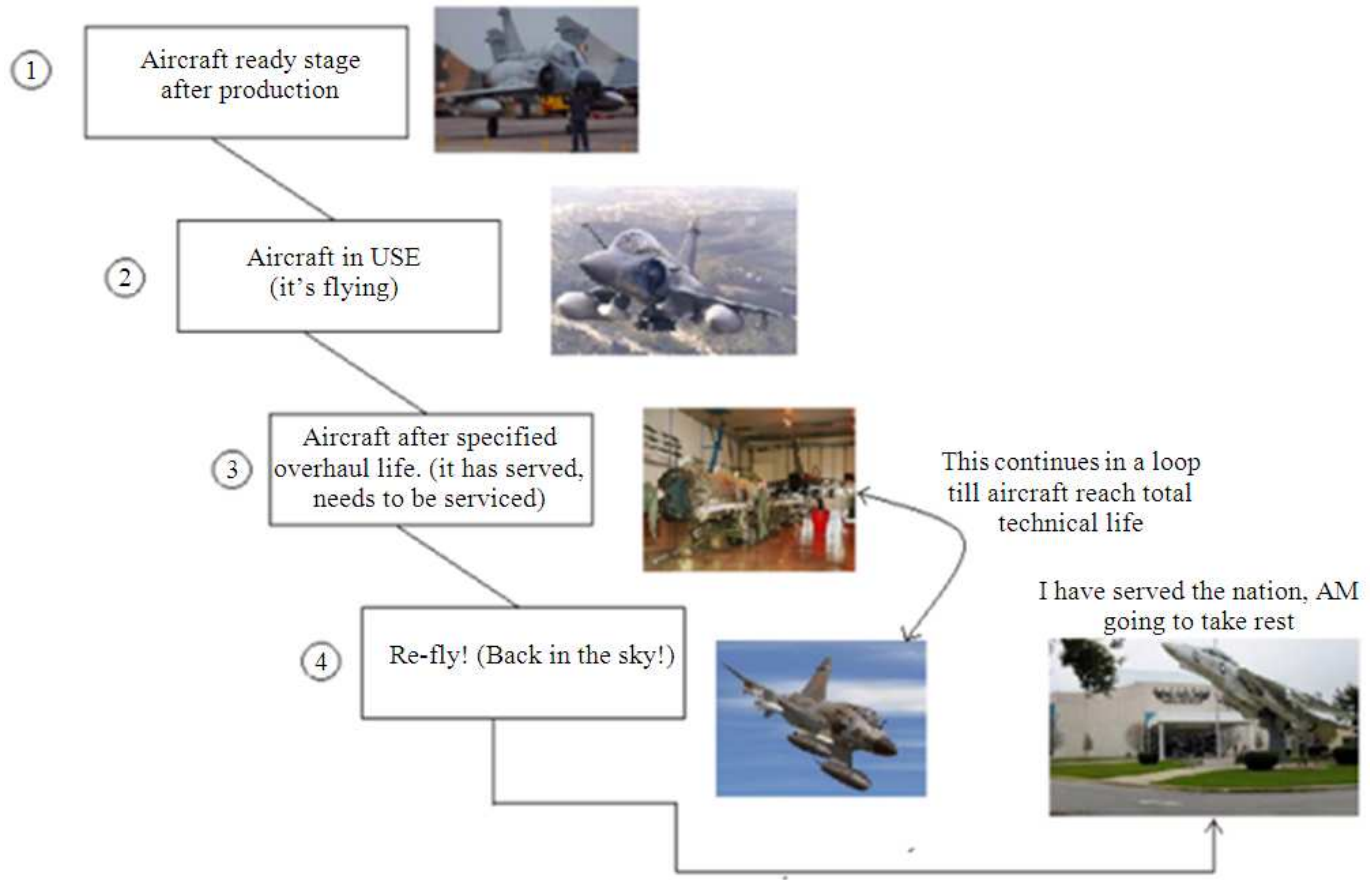

Aircraft-life cycle

Fig. 1. Aircraft Life cycle

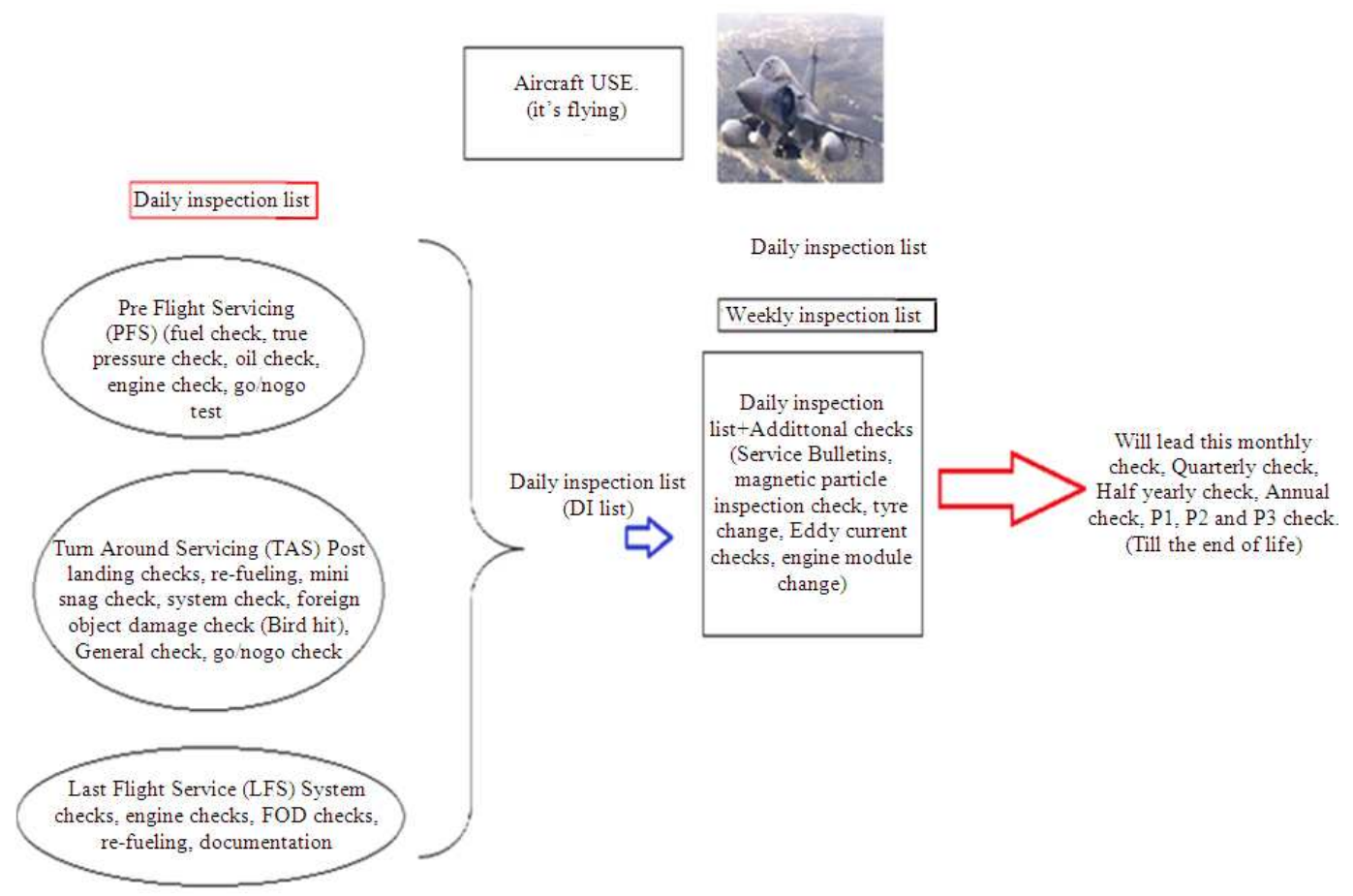

Fig. 2. Aircraft utilisation cycle 
Balachandran A. et al. / Journal of Computer Science 10 (3): 403-410, 2014

Aircraft after specified
overhaul life. (it has
served, needs to be
$\quad$ serviced)
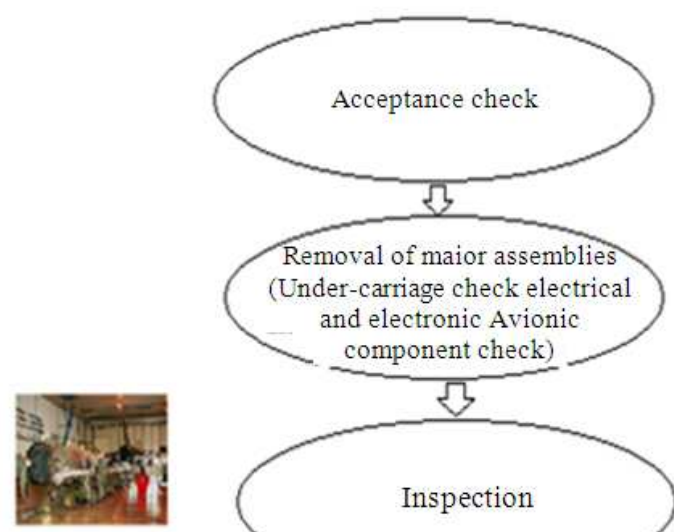

Removal of maior assemblies

Under-carriage check electrical and electronic Avionic
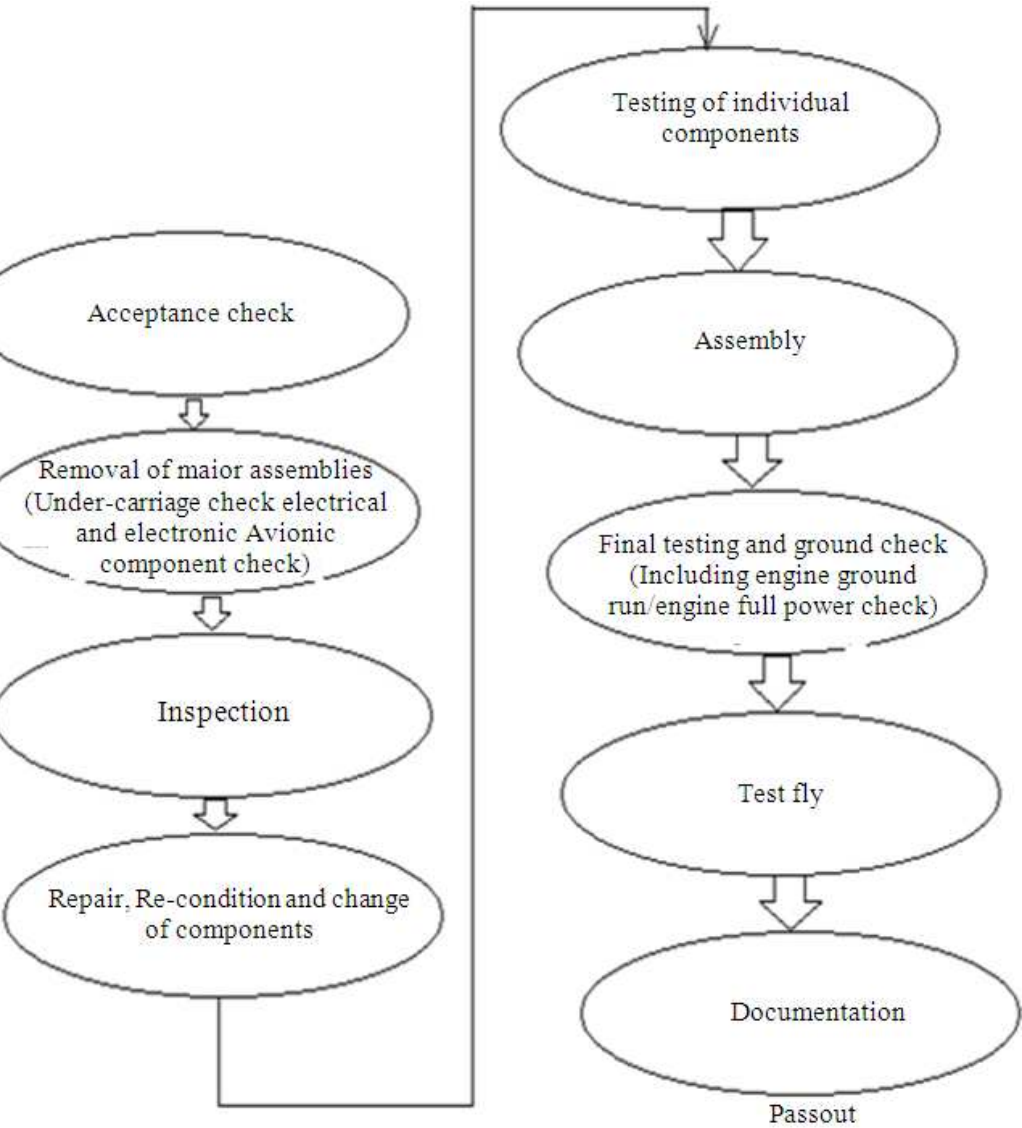

Fig. 3. Aircraft maintenance cycle

(5) Upper skin:

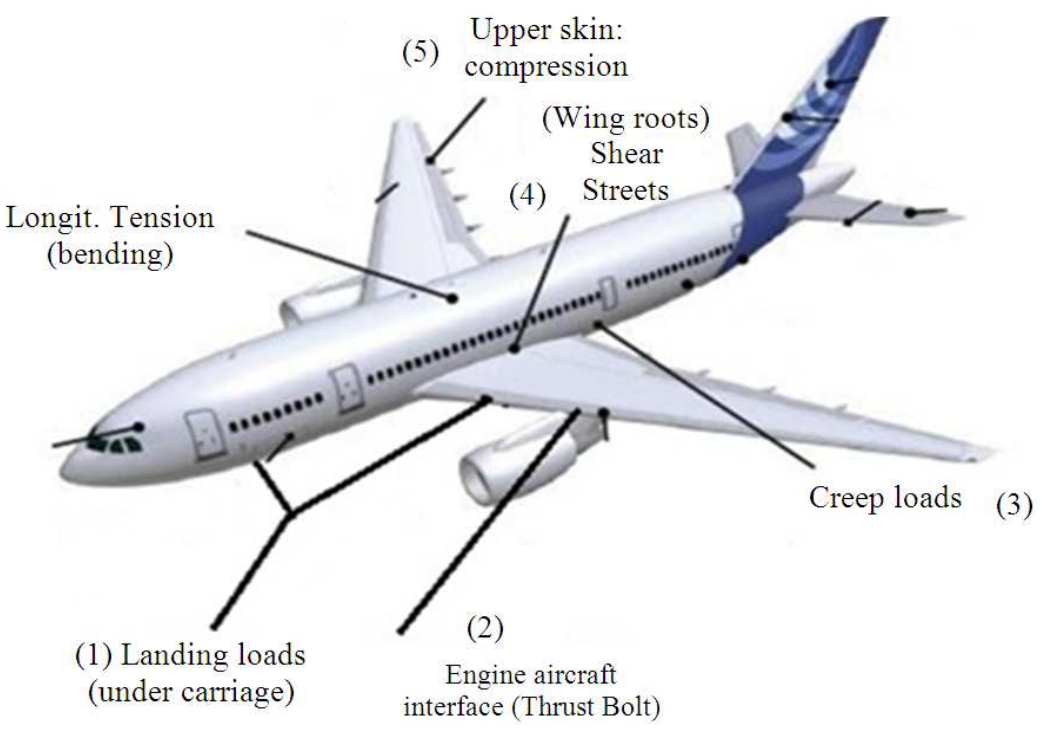

Fig. 4. Points under consideration for test bed 
Table 1. Various testing process and period

\begin{tabular}{lll}
\hline S. No. & Test name & Time \\
\hline 1 & Preflight & {$[$ Every landing] } \\
2 & Terminal halt & {$[12 \mathrm{~h}]$} \\
3 & Layover check & {$[24 \mathrm{~h}]$} \\
4 & Check A & {$[125 \mathrm{~h}]$} \\
5 & Check 3A & {$[375 \mathrm{~h}]$} \\
6 & Check b & {$[750 \mathrm{~h}]$} \\
7 & Check2B & {$[1500 \mathrm{~h}]$} \\
8 & Check C & {$[3000 \mathrm{~h}]$} \\
9 & Check 2C & {$[6000 \mathrm{~h}]$} \\
10 & Check 3C & {$[9000 \mathrm{~h}]$} \\
11 & Check 4C & {$[12000 \mathrm{~h}]$} \\
12 & Check 5C & {$[15000 \mathrm{~h}]$} \\
13 & Check D & {$[18000 \mathrm{~h}]$} \\
\hline
\end{tabular}

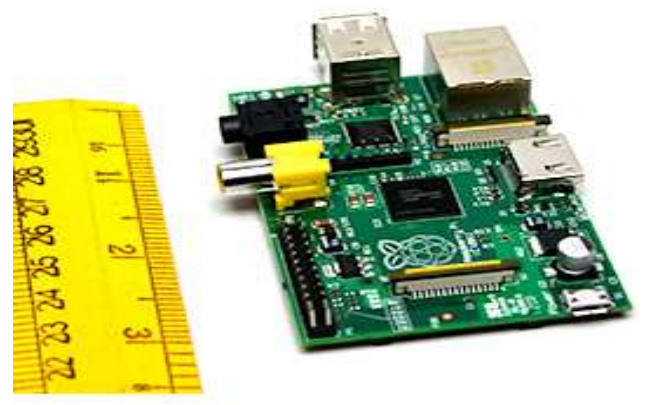

Fig. 5. Raspberry pi

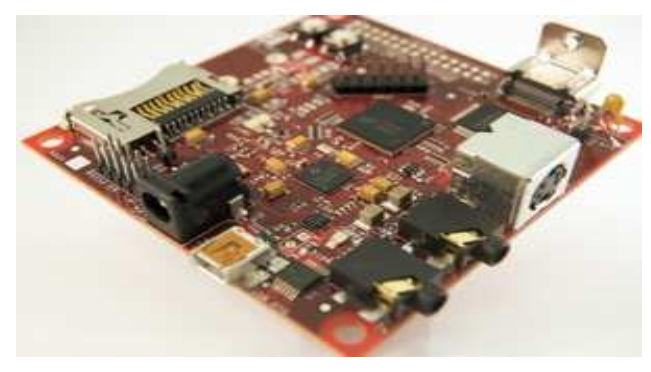

Fig. 6. Beagle board

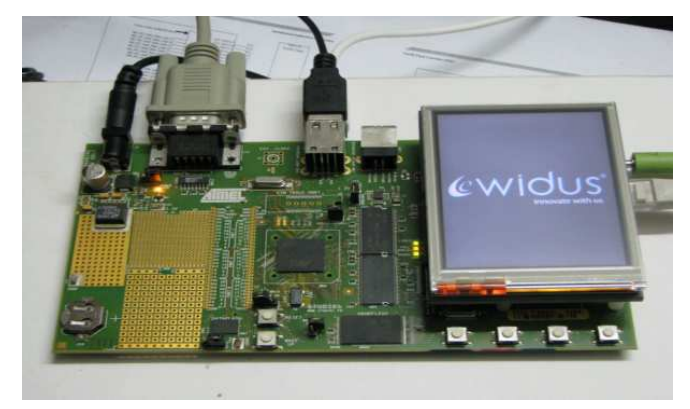

Fig. 7. ATMEL

\section{CONCLUSION}

Based on the above factors and ideas, a test bed has been set up to collect the data from the various factors and an algorithm to calculate the fatigue index will be proposed based on the results. Once the results are verified by the Indian Air force, the detailed report will be released in the next article. This study brings a conceptual solution, which has an embedded system in place which would fetch all the critical information during flight and with which optimum usage can be obtained and thereby increasing the effective flying time of the flight through which we get better results economically, technically and avoiding over maintenance. This will eventually find out a way to exploit the aircraft more effectively with cutting down the unnecessary cost. One area of improvement is how much secured the obtained data has to be kept. Since this is the initial stage of research, we have not paid attention to that arena (Meseroll et al., 2007).

Sausen et al. (2004) has given an alarm on pollution related with aviation which is one factor to be taken into consideration when a solution is proposed.

\section{ACKNOWLEDGEMENT}

We thank PRIST University and Amrita University for support and guidance provided. Also first author expresses his sincere gratitude to his guide Dr. P.R. Suresh.

\section{REFERENCES}

Feng, D., P. Singh and P. Sandborn, 2007. Lifetime buy optimization to minimize lifecycle cost. Proceedings of the Aging Aircraft Conference, (AAC' 07), University of Maryland.

Kechida, S. and N.E. Debbache, 2005. Failure diagnosis on discrete event systems. Am. J. Applied Sci., 2: 1547-1551. DOI: 10.3844/ajassp.2005.1547.1551

Li, Y., Z. Wang, Y.L. Chen, Y. Zhang and W.S. Sun, 2012. Research on compiling fatigue load spectrum of individual aircraft and analysis of fatigue life based on flight data. Proceedings of the IEEE Conference on Prognostics and System Health Management, May 23-25, IEEE Xplore Press, Beijing, pp: 1-5. DOI: 10.1109/PHM.2012.6228937

Meseroll, R.J., C.J. Kirkos and R.A. Shannon, 2007. Data mining navy flight and maintenance data to affect repair. Proceedings of the IEEE Autotestcon, Sept. 17-20, IEEE Xplore Press, Baltimore, MD., pp: 476481. DOI: 10.1109/AUTEST.2007.4374256 
Balachandran A. et al. / Journal of Computer Science 10 (3): 403-410, 2014

Sausen, R., C. Fichter and G. Amanatidis, 2004. Aviation, Atmosphere and Climate, number 83 in Air pollution research report. Proceedings of an International Conference Aviation, Atmosphere and Climate (AAC), (AAC' 04).
Westervelt, K., 2005. Transforming a maintenance ground station. Proceedings of the IEEE Aerospace Conference, Mar. 5-12, IEEE Xplore Press, Big Sky, MT., $\quad$ pp: 3723-3731. DOI: 10.1109/AERO.2005.1559678 